\title{
Customized Attachment for Cheek Plumper: A Case Report
}

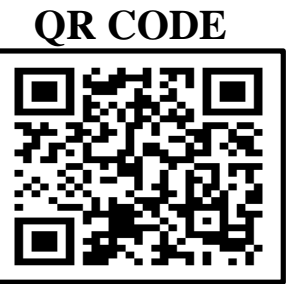

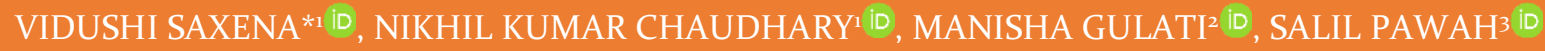

The goals of replacement of teeth with a complete denture are not limited to only providing the patient with the ability to chew food comfortably. Due to the increasing demands and consciousness of the patients regarding esthetics, prosthodontist must emphasize on not just the function but also overall appearance of the patients. The loss of support of the facial musculature is of great concern in treating completely edentulous patients. Sunken cheeks are one of the major consequences of flaccid facial musculature. The incorporation of cheek plumpers in the dentures has improved the appearance of patients with such conditions. They are noninvasive and straightforward to fabricate. Various attachments may be used for this purpose depending upon the case present. This case report involves 2 cases with different techniques for the attachment of detachable cheek plumpers.

KEYWORDS: Detachable Cheek Plumper, Denture Esthetics, Sunken Cheeks, Unconventional Dentures

\section{INTRODUCTION}

The replacement of missing teeth should not be the sole purpose of prosthetic rehabilitation of a completely edentulous patient. Restoration of all the functions along with esthetics must form the ultimate aim of the clinician. As the age progresses, loss of subcutaneous fat and elasticity of the tissue causes the cheeks to become slumped. Usually, certain facial structures get support from denture flanges, but sometimes the denture flange does not provide adequate support to the facial musculature and requires additional support. ${ }^{1}$

According to Jamieson $\mathrm{CH}^{2}$, "fitting the personality of the aged patient is often more difficult than fitting the denture to the mouth." Proper extension of denture borders during the complete denture fabrication may help to achieve most of the esthetics by providing proper support to the musculature. But in some cases due to prolonged edentulism patient presents with sunken cheeks. In such cases the need to add extra support in the form of cheek plumpers may be required. Conventional cheek plumper is single-unit prosthesis with extension near the premolar-molar region that supports the cheek. ${ }^{3}$ Such designs have a disadvantage as it adds extra bulk to the denture leading to its frequent dislodgement during speech and function. To overcome these limitations, detachable cheek plumpers have been used in the past which have provided improved results. This case series includes two cases of cheek plumpers with different attachments based on the requirement of the case. A written consent was obtained from both cases prior to writing the manuscript.

\section{CASE REPORT 1}

A 6o-year-old female patient, completely edentulous, reported to the Department of Prosthodontics with the chief complaint of missing teeth. Upon taking case history it was noted that the patient was edentulous for 4 years and had not worn any dentures previously. The overall appearance of the patient was malnourished with sunken cheeks leading to poor esthetics. Patient's expectation with the denture included, adequate function as well as esthetics. All the steps for a complete denture fabrication were followed till the try in stage. The patient had a class 3 ridge relation and due to the prognathic mandible the musculature adjacent to the maxilla wasn't well supported. Cheek plumper was planned for the patient at the try in stage but due to very shallow flanges and compromised space, the available attachment choices for the detachable cheek plumper were not satisfactory.

A customized attachment was hence fabricated for the patient using autopolymerising acrylic resin and 21 gauge orthodontic wire. Cheek plumper was made using impression compound and it was moulded according to the movements of the patient's facial 
muscles. Once satisfactory fullness was achieved the cheek plumper was retrieved from the denture base and orthodontic wires were incorporated in it. Two wires were bent to make a J loop and the longer arms were embedded in the compound. An acrylic sleeve was fabricated over the arm projecting outside the plumper. After complete polymerisation of resin, the sleeve was checked for smooth gliding over the wires for insertion and removal. This acrylic sleeve was kept narrow corresponding to the decreased flange height. After marking the rough dimensions, a window was then cut in the denture to fit the acrylic sleeve block. The position of the cheek plumper was checked with the acrylic block engaged within the window (figure 1 ).

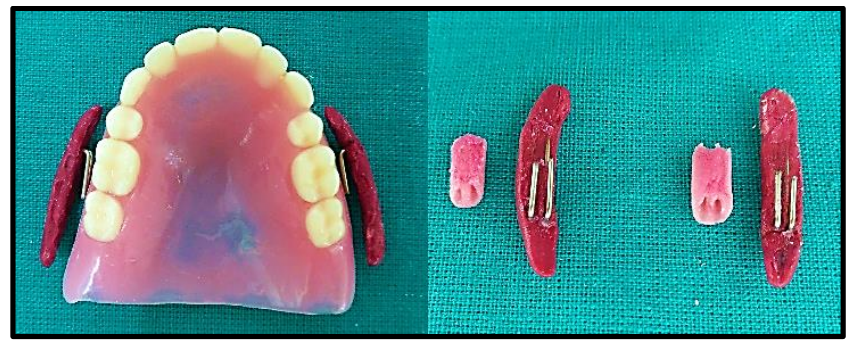

Figure 1. Wires Incorporated in the Cheek Plumper Made with Impression Compound. Corresponding Sleeves Fabricated with Autpolymerizing Acrylic Resin

Once confirmed, the acrylic block was incorporated in the denture using autopolymerising aclyric resin. The cheek plumpers were flasked and dewaxing was done followed by packing with heat cure acrylic resin. Finishing and polishing was done for the cheek plumper as well as the denture with the acrylic sleeve (figure 2). The attachment system was checked once again and the patient was trained for removal, cleaning and reinsertion of the attachment. The patient was satisfied with the final outcome (figure 3). This method of attachment is conservative as it requires minimal space and also cost friendly as it can be fabricated easily with materials readily available to the dentist.

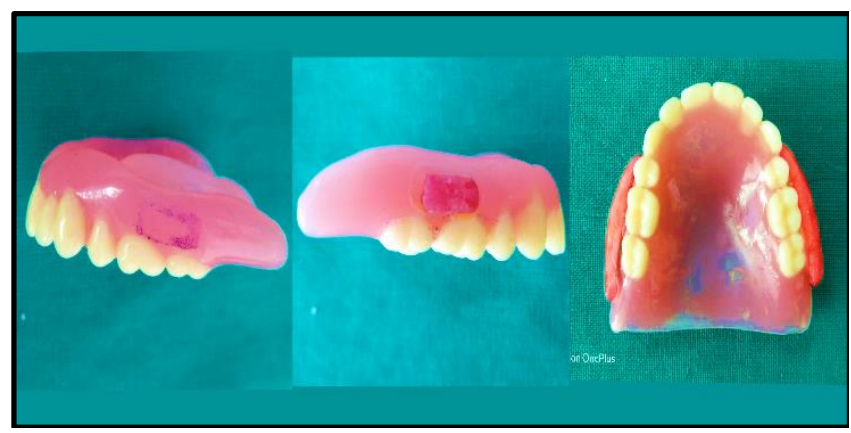

Figure 2. Dimensions Marked and Window Created in the Denture to Insert the Acrylic Sleeve Block

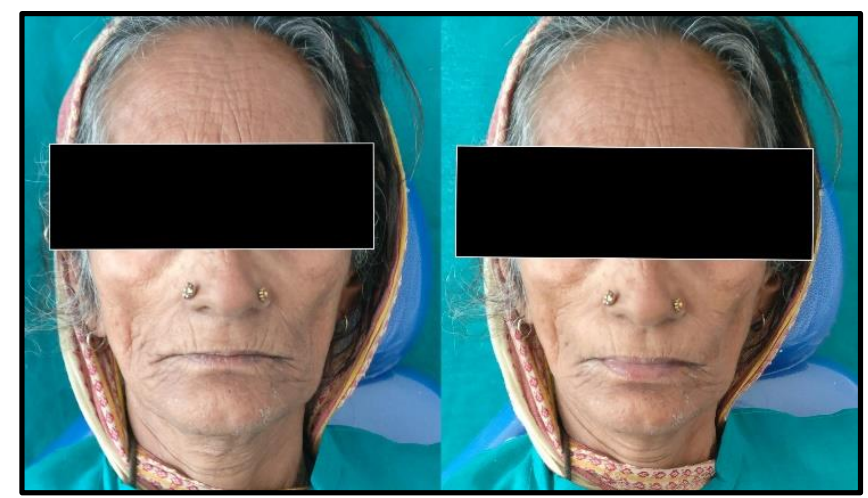

Figure 3. Patient's Appearance Without the Cheek Plumpers (Left) And with The Cheek Plumper Attached to the Denture (Right)

\section{CASE REPORT 2}

A 38-year-old patient reported to the Department of Prosthodontics; with the chief complaint of missing teeth leading to poor esthetic appearance. Case history revealed patient lost his anterior teeth 6 months back and posterior teeth 2 years back and never got them replaced. It was noted on extraoral examination that patient had sunken cheeks which were not esthetic and since the patient belonged to a younger age group, he was conscious regarding the same and sought improved esthetics.

Conventional steps for a complete denture were followed till the try in stage. Impression compound was adapted on the sides of the maxillary and mandibular denture base on the buccal aspect (figure 4). Patient was asked to make functional movements for moulding the impression compound. The esthetics was evaluated and required adjustments were made. Patient's consent was obtained for final fabrication of the dentures with the cheek plumpers. Since the cheek plumpers were bulky, hollow cheek plumpers were planned for the patient to reduce the weight of the prosthesis. Dewaxing was done followed by lost salt technique for the packing stage(figure 5). After the final processing, a hole was made on the surface of the cheek plumpers where the attachment was to be placed. This same hole was used for washing out the salt crystals from the plumper. Push button attachments were used to attach cheek plumper with denture base. Two $2 \mathrm{~mm}$ deep and $5 \mathrm{~mm}$ diameter holes were made on the posterior flange of the maxillary denture base and 1 hole of similar dimensions was made in the mandibular denture. The male part of the push button was attached to the denture base, and female part was attached to the cheek plumper with the help of auto-polymerizing resin (figure 6). Finishing and polishing was performed 


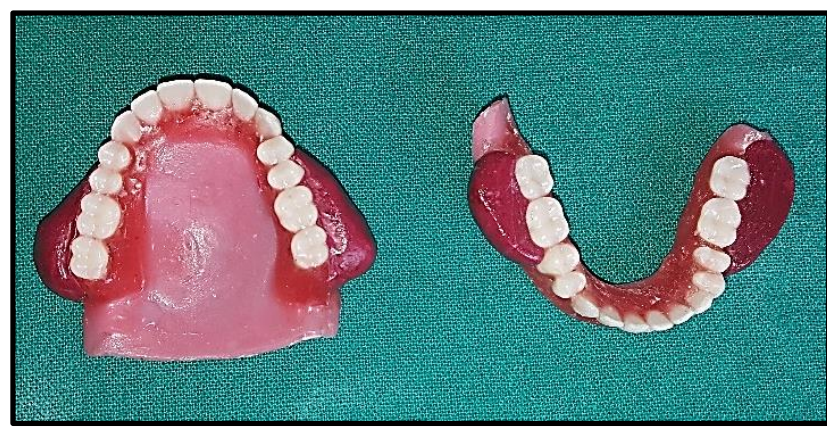

Figure 4. Cheek Plumpers In Impression Compound Attached to Maxillary and Mandibular Dentures, Modified According to Patient's Functional Movements

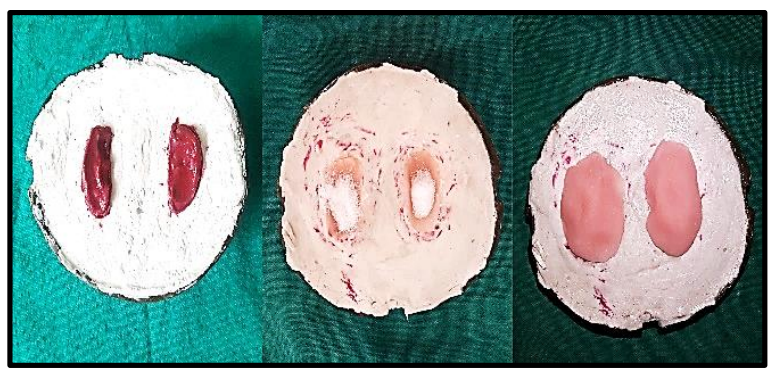

Figure 5. Flasking And Acrylization of the Cheek Plumpers using the "Lost Salt Technique"

and the patient was given post-operative instructions (figure 7).

\section{DISCUSSION}

Denture esthetics is not only limited to the SPA concept where the emphasis is always given upon the selection of the form, shape, shade of teeth given in a denture. It is more about harmonization between the artificial and natural tissues. ${ }^{4}$ Loss of subcutaneous fat and elasticity of the connective tissue produces the hollow cheeks seen in the aged. Cheek plumpers or cheek lifting appliances have been used previously for the purpose of improving esthetics and psychological profile in patients. Conventional cheek plumpers, when used, add to the weight of the prosthesis, can cause muscle fatigue, and make the denture unstable. ${ }^{5}$ They also make insertion and removal of the prosthesis difficult, particularly for patients with xerostomia. ${ }^{6}$ The space that exists between the cheek and the denture flange along with the height of flange varies from patient to patient. ${ }^{1}$ Hence the type of cheek plumper attachments that must be used in case of detachable cheek plumpers is a decision which is to be made by the operator. In the present case, detachable cheek

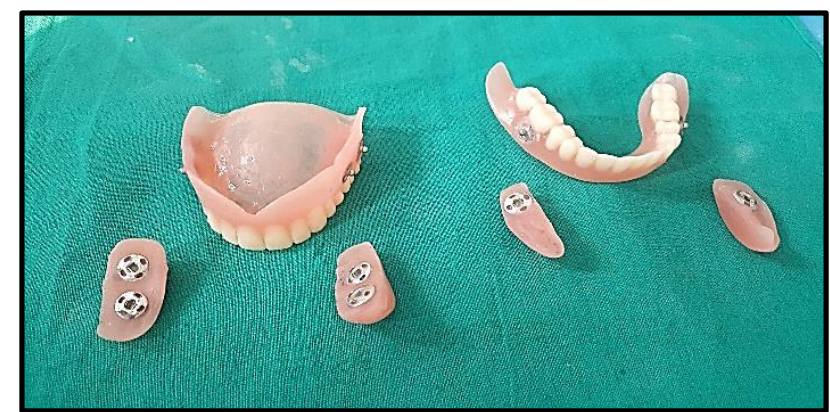

Figure 6. Cheek Plumpers in Heat Cure Acrylic Resin with Push Button Attachments

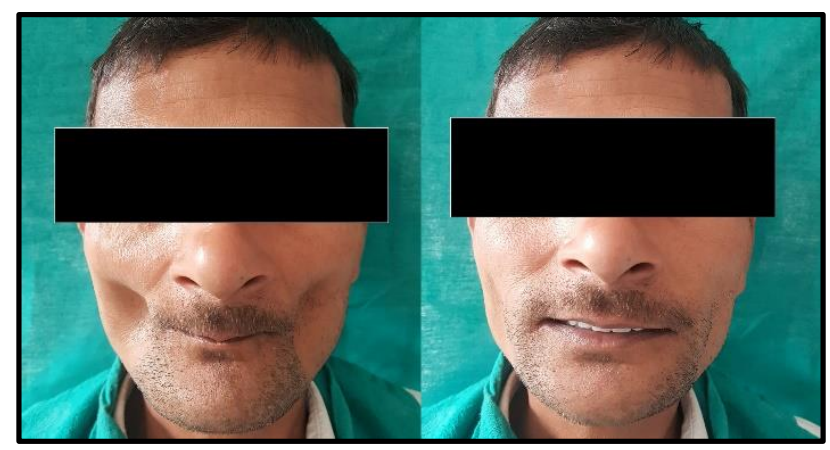

Figure 7. Patient's Appearance without the Cheek Plumpers (Left) and with the Cheek Plumper Attached to the Denture (Right)

plumper prosthesis were planned to reduce weight of the final prosthesis and they allow the patient to remove them when and if required. Lost salt technique was incorporated in fabrication of plumpers to further reduce the weight of the prosthesis. Clinical magnets as attachments are good options and may be used but since they are expensive and not affordable for every patient, alternatives such as push-button attachments or the ones fabricated from easily available material, like autopolymerising resin and stainless steel wires, make affordable and quick means to attach cheek plumper to the denture. ${ }^{7}$

\section{CONCLUSION}

This case report describes a simple, effective and inexpensive treatment to improve facial appearance in patients with sunken cheeks. The attachment using acrylic sleeve and stainless steel wire is easy to make with readily available material and may be used in patients with narrow flanges. The lost salt technique is used to create hollow plumpers in cases where cheek plumpers are placed in both the maxillary and mandibular denture, to reduce the overall weight of the prosthesis for the comfort of the patient. 


\section{REFERENCES}

1. Bhushan P, Aras MA, Coutinho I, Rajagopal P, Mysore AR, Kumar S. Customized cheek plumper with friction lock attachment for a completely edentulous patient to enhance esthetics: a clinical report. Journal of Prosthodontics. 2019;28(1):e1-5

https://doi.org/10.1111/jopr.12591

2. Jamieson $\mathrm{CH}$. Geriatrics and the denture patient. J Prosthet Dent. 1958;8:8-13.

3. Aggarwal P, Gupta MR, Pawah S, Singh A. An Innovative Technique to Improve Complete Denture Aesthetics Using Cheek Plumper Appliance: A Case Report. Int J Oral Health Med Res. 2016;3(2):51-4.
4. Lingegowda $A B$, Shankaraih M, Bhallaiah $P$. Magnet retained cheek plumpers in complete denture patient. Int J Dent Clinics. 2012;4:65-6.

5. Sunil Kumar MV, Rao H, Sohi KS. Artificial cheek plumpers: a step ahead in denture aesthetics-a case report. Indian J Stomatol. 2011;2:134-7.

6. Pudi S, Kota S, KVG Ch K, Kaladi SR, Gade RR. An Innovative Technique Using a Stainless Steel Double Die Pin Retained Cheek Plumper in Complete Denture Esthetics: A Case Report. Cureus 11(11): e6197. https://doi.org/10.7759/cureus.6197

7. Keni NN, Aras MA, Chitre V. Customised attachments retained cheek plumper prosthesis: A case report. The Journal of Indian Prosthodontic Society 2012;12(3):198-200.

Cite this article as:

Saxena V, Chaudhary NK, Gulati M, Pawah S. Customized Attachment for Cheek Plumper: A Case Report. Int Healthc Res J. 2021;4(12):CR9-CR12. https://doi.org/10.26440/IHRJ/0412.03400

\section{AUTHOR AFFILIATIONS: (*Corresponding Author)}

1. PG Student [(https://orcid.org/oooo-0003-1204-669o, Vidushi Saxena), (https://orcid.org/oooo-00o2-9786-9903, Nikhil Kumar

Chaudhary)]

2. Professor (https://orcid.org/oooo-ooo1-9732-8448)

3. Professor \& HOD (https://orcid.org/oooo-00o1-8766-2434)

Department of Prosthodontics, Sudha Rustagi College of Dental Sciences and Research, Kheri Mor, Sector-89, Faridabad, Haryana- 121002 